\title{
Effect of Collaboration Through Social Media on Collaborative Overload, Burnout and Employee Engagement
}

\author{
Shilpa Jain, Nitya Khurana and Bhawna Soni \\ University School of Management Studies, Guru Gobind Singh Indraprastha University, New Delhi, India
}

Correspondence Author: Ms. Bhawna Soni, University School of Management Studies, Guru Gobind Singh Indraprastha University, New Delhi, India

Received date: 11 March 2019, Accepted date: 22 April 2019, Online date: 30 April 2019

Copyright: (C) 2019 Shilpa Jain, et al. This is an open-access article distributed under the terms of the Creative Commons Attribution License, which permits unrestricted use, distribution, and reproduction in any medium, provided the original author and source are credited.

\begin{abstract}
Collaboration has become one of the most important buzzwords in Corporate HR today. Organisations are increasingly focussing on working together for a common goal to reap the benefits of synergy. Social media, these days play a major role in collaborating employee efforts through different instant messaging apps. Organisations are using these ways to collaborate employee efforts with a view to not only enhance the productivity and profitability but also to improve engagement of the employees towards organisation. But, excessive collaboration leads to collaborative overload and eventually burnout. The present study aims to understand whether collaboration through social media leads to employee engagement or it leads to collaborative overload and burnout among employees of the organisation. A self-administered questionnaire was used to collect primary data from 136 respondents. The results of the study revealed that social media collaboration significantly impact collaborative overload and collaborative burnout while it does not have an impact on employee engagement. Collaborative overload has a significant positive impact on burnout but an insignificant relationship with employee engagement. And, burnout has a significant negative impact on employee engagement.
\end{abstract}

Key words: Collaboration, Social Media, Collaborative Overload, Collaborative Burnout, Employee Engagement

\section{INTRODUCTION}

Collaboration in today's time is one of the most common ways of doing business. Harvard Business Review highlighted that collaborative activities in the workplace have increased by more than $50 \%$ over the last two decades. Even though there is much to appreciate about collaborative way of doing work, it has now in some organization exceeded to $80 \%$ of the total work done by them. The time employees are using for meetings, replying to emails, attending phone calls has exceeded such limits that the employee is left with very little time to finish some other important work on their own. Pertaining to this regular feature of collaboration through social media during office hours, employees need to take their work home, which then causes stress and burnout among hardworking and talented employees. In teamwork, it is usually the trend that those that are capable and willing to help they get a reputation for being helpful and knowledgeable and then slowly but gradually this leads to them doing most of the work for the team. Cross, Rebele, and Grant [1] argued that more than 300 organizations has a lopsided distribution of collaborative work. In most cases, $20 \%$ to $35 \%$ of the work is done by the $3 \%$ to $5 \%$ of the employees. Their productivity exceeds the productivity of the whole team combined. But after a time, doing others work leads them to feel overburdened and agitated with their working condition, they feel less satisfied for the work they are doing and their performance in their personal arena starts to decline and so does their engagement in the organization. They start putting in only the bare minimum necessary. And now with the inclusion of instant messaging apps in the mix, things have become even worse. They have already been taking their personal assignments home but now that they can easily be contacted at home they are expected to be available to their team members even outside office hours. The ability to be able to message a co-worker with their problem has given lazy employees even more power. And those who thrive on good results are left to do their work. Most of the times the work comes at odd times and it becomes a hassle to ignore it. All of this in the end causes a burnout in employees and decreases their engagement in the organization. The present research aims to understand the relationship of collaboration through social media with collaborative overload, burnout and employee engagement.

\section{Literature Review}

Harmon [2] construed that leaders are increasingly focusing on the impact of collaboration on the most generous employees. The major challenge is that, while working in teams many people have become an expert of shifting their work on someone else. In some organizations people expert in this art, they keep moving workaround by holding meetings and keeping others engaged, and they never actually do the work they were supposed to have done.

Cross, Rebele, and Grant [1], construed that over the last two decades the time used by employees and managers has increased by more than $50 \%$. According to them, the benefits of collaboration have not gone unnoticed but the dark side of collaboration remains unrecognized. The ill-effects of excessive and unmanaged collaboration are many. If the demand for collaboration is too high and is not evenly spread, it can result into workflow bottleneck and employee burnout. They preached that leaders must learn to manage collaboration in their company. They should try to incentivize people to learn how to collaborate effectively.

There is a dark side of social media use. Employees find work-related use to be an intrusion to their personal lives while also increasing life to work conflict. [3]. The study reveals that the current implementation of policies related to social media use, are not enough to protect the employees from the negative consequences of social media usage like work life conflict and ultimately exhaustion. The findings indicated that there is a need to actively work to reduce the boundary conflict on workers' well being, which is a result of increased social media use at work. 
Cross and Gray [4] conducted a study found that in the time where new collaboration technologies are being invented there is a constant pressure for more interaction. It is so much so that it becomes difficult for the leaders to keep employees focused on the tasks that will create more value for the organization. They found that expecting the employees to both collaborate more and to complete their own personal work at the same time in most cases leads to overload and burnout and also decreases the productivity of the employees. They also found that leaders who continuously try to eradicate the unnecessary and wasteful collaboration from their organization help employees become more productive in their jobs. This results in employees not having to choose between equally important tasks, which potentially cuts back their stress levels. The change in the organizational culture means that the efficient collaborat ors are acclaimed and their practices are held up as a mirror for others.

Wisniewski and $\mathrm{Lu}[5]$ conducted a study which concluded that increased usage of information technology in the workplace is at times leads to productivity loses.

Rabey [6] theorized that the leaders and managers keep promoting teamwork for its benefits. Teams might have the collective strength that completes the work, but the ideas that guide the teamwork belong to the individuals. Yet it has become quite significant for the managers to accept the undiscovered potential of employees they regard as team members. Otherwise, their potential gets lost.

\section{The rationale of the Study}

With the spur of social media messaging among individuals, managers in the organizations these days are increasingly focusing on collaboration through social media. Most of the work is assigned and team discussions are conducted through social media messaging whether during office hours or beyond the office hours. Therefore there is a need to assess the impact of collaboration through social media on collaborative overload, burnout and employee engagement.

\section{Research Methodology \\ 4.1 Objective of the Study}

- To study the relationship of collaboration through social media with collaborative overload, burnout and employee engagement.

- To study the impact of collaboration through social media on collaborative overload, burnout and employee engagement.

- To study the impact of collaborative overload on burnout and employee engagement.

- To study the impact of burnout on employee engagement.

- To study the mediation effect of burnout on the relationship of collaboration through social media and employee engagement.

- To study the mediation effect of burnout on the relationship of collaborative overload and employee engagement.

4.2 Sample

The sample consisted of 136 respondents, out of which 61 were females and 75 were males working in private and public sector organizations. Out of 136 respondents, 120 were from the age group 18-35, 16 were from age group 36-55 and there was no one from the age group of above 55 years. Out of 136 respondents, 119 worked in Private Sector and 17 worked in Public Sector. Also, 84 respondents had work experience of up to 5 years, 24 respondents had work experience from 6-10 years, 25 respondents had work experience from 11-20 years and 3 respondents had work experience of 21 years and more. Out of 136 respondents, 71 were entry level managers, 58 were middle level managers, and 7 were senior level managers. Table 1 shows the demographic profile of the respondents.

\subsection{Tools Used}

- Collaboration through Social Media: A 10 itemed questionnaire was constructed to measure collaboration through social media. The validity of the questionnaire was established by confirmatory factor analysis. The cronbach alpha reliability score was calculated as 0.672 .

- Collaborative Overload: A 16 itemed questionnaire was constructed to measure the collaborative overload. The validity of the questionnaire was established by confirmatory factor analysis. The cronbach alpha reliability score was calculated as 0.818 .

- Burnout: A 10 itemed questionnaire was constructed to measure employee burnout. The validity of the questionnaire was established by confirmatory factor analysis. The cronbach alpha reliability score was calculated as 0.852 .

- Employee Engagement Scale: A 26 itemed employee engagement scale developed by Lather and Jain (2014) was used to measure Employee Engagement. The scale had six dimensions of employee engagement, that is, organizational commitment, job satisfaction, advocate, intent to stay, pride and emotional connect. The reliability score of various dimensions were Job Satisfaction (.870), Organizational Commitment (.858), Advocate (.831), Pride (.891), Intent to Stay (.806), and Emotional Connect (.784).

\section{Results and Discussions}

Pearson Correlation was applied to understand the relationship between Collaboration through Social Media, Collaborative Overload, Burnout and Employee Engagement. Table 2 shows the Correlation coefficient between the above mentioned constructs wherein Collaboration through Social Media has a significant Positive relationship with Collaborative Overload and burnout, and an insignificant relationship with Employee Engagement, Collaborative Overload has a significant positive relationship with Employee Burnout and an insignificant relationship with Employee Engagement, and lastly Burnout has a significant negative relationship with Employee Engagement.

Linear Regression analysis was applied to see the impact of Collaboration through Social Media on Collaborative overload on employees, Employee Burnout and Employee Engagement. It was found that Collaboration through Social Media has a significant positive impact of $16.5 \%$ and $9.7 \%$ on Collaborative Overload and Employee Engagement, whereas it has a very insignificant impact on Employee Engagement of 1.1\%. (Table 3). On regressing Collaborative Overload with Employee Burnout and Employee Engagement it was found that Collaborative Overload has significant positive impact of 39.5\% on Employee Burnout, and has an insignificant impact of $1 \%$ on Employee Engagement (Table 4). On regressing with Employee Burnout it was found that it has significant positive impact of 9.2\% on Employee Engagement (Table5).

To study the mediation effect Sobel statistics was applied. Figure 1 shows the model wherein burnout mediates the relationship of collaboration through social media and employee engagement. As we have already discussed that collaboration through social media has an insignificant impact on employee engagement (Table 3) but this relationship is mediated by burnout. Burnout has a significant impact on employee engagement (Table 5). On analyzing the data through Sobel test it was revealed that burnout significantly mediates collaboration through social media and employee engagement (Table 6). Similarly, figure 2 shows the model wherein burnout mediates the relationship of collaborative overload and employee engagement. It is evident that burnout significantly mediates the relationship of collaborative overload and employee engagement (Table 7).

\section{Conclusion}

As evident from the results of the present study collaboration through social media like instant messaging apps have not only affected the work life balance but also builds a constant stress and peer pressure among employees to be available 24X7. This is creating an overload on employees to work hard and hard without any recreational time left to regain the mental, emotional and physical calm. This eventually leads to a burnout situation and thus leads to disengaged employee. Disengaged employees lack motivation to work hard for the organization and thereby reduces the profitability of the organizations. Organizations must therefore, try to create a work life balance and make efforts to engage their employees.

\section{Limitation of the Research}

The study is limited to a sample of 136 employees of Delhi/NCR. The finding of this study therefore may not have universal applicability to other organizations. Also, since the study is conducted in India, its applicability is limited to other countries. 
Table 1: Respondent Profile

\begin{tabular}{|c|c|c|}
\hline \multirow{2}{*}{ Gender } & Male & 75 \\
\cline { 2 - 3 } & Female & 61 \\
\hline \multirow{3}{*}{ Age Group } & $18-35$ years & 120 \\
\cline { 2 - 3 } & $36-55$ years & 16 \\
\cline { 2 - 3 } & $55+$ years & 0 \\
\hline \multirow{2}{*}{ Sector Of Employment } & Private & 119 \\
\cline { 2 - 3 } & Public & 17 \\
\hline \multirow{3}{*}{ Work Experience } & $0-5$ years & 84 \\
\cline { 2 - 3 } & $10-20$ years & 24 \\
\cline { 2 - 3 } & $11-20$ years & 25 \\
\hline \multirow{2}{*}{$\begin{array}{c}\text { Employed on which level of } \\
\text { Management }\end{array}$} & Entry Level Management & 71 \\
\cline { 2 - 3 } & Middle Level Management & 58 \\
\cline { 2 - 3 } & Senior Level Management & 7 \\
\hline
\end{tabular}

Table 2: Correlation Coefficients showing the relationship between the constructs

\begin{tabular}{|c|c|c|c|c|}
\hline & SM_Msg & CO & Burnout \\
\hline SM_Msg & 1 & & \\
\hline CO & & & \\
\hline & .413 & 1 & & \\
\hline Burnout & $(0.000)$ & .632 & $(0.000)$ & \\
\hline EE & .323 & -.132 & -.315 & \\
\hline
\end{tabular}

Here SM_Msg means Social Media Messaging, CO means Collaborative Overload, and EE means Employee Engagement.

Table 3: Regression analysis to show the impact of Collaboration through social media on Collaborative Overload, Burnout and Employee Engagement

\begin{tabular}{|c|c|c|c|c|c|c|c|c|}
\hline & \multirow[t]{2}{*}{ F(Sig) } & \multirow[t]{2}{*}{$\mathbf{R}^{2}$} & \multirow[t]{2}{*}{$\operatorname{Adj} R^{2}$} & \multicolumn{2}{|c|}{$\begin{array}{c}\text { Unstandardised } \\
\text { Coefficient }\end{array}$} & \multirow[t]{2}{*}{$\begin{array}{c}\text { Standardized } \\
\text { Beta }\end{array}$} & \multirow[t]{2}{*}{$\mathbf{t}$} & \multirow[t]{2}{*}{ Sig } \\
\hline & & & & $\beta$ & Error & & & \\
\hline \multirow[t]{2}{*}{$\mathrm{CO}$} & 27.617 & .171 & .165 & .421 & .080 & .413 & 5.255 & $(0.000)$ \\
\hline & $(0.000)$ & & & & & & & \\
\hline \multirow[t]{2}{*}{ Burnout } & 15.555 & .104 & .097 & .481 & .122 & .323 & 3.944 & $(0.000)$ \\
\hline & $(0.000)$ & & & & & & & \\
\hline \multirow[t]{2}{*}{$\mathrm{EE}$} & 2.540 & .019 & .011 & -.160 & .101 & -.136 & -1.594 & .113 \\
\hline & $(.113)$ & & & & & & & \\
\hline
\end{tabular}

Table 4: Regression analysis to show the impact of Collaborative Overload on Burnout and Employee Engagement

\begin{tabular}{|c|c|c|c|c|c|c|c|c|}
\hline 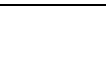 & \multirow[t]{2}{*}{ F(Sig) } & \multirow[t]{2}{*}{$\mathbf{R}^{2}$} & \multirow[t]{2}{*}{$\operatorname{Adj} R^{2}$} & \multicolumn{2}{|c|}{$\begin{array}{l}\text { Unstandardised } \\
\text { Coefficient }\end{array}$} & \multirow[t]{2}{*}{$\begin{array}{c}\text { Standardized } \\
\text { Beta }\end{array}$} & \multirow[t]{2}{*}{$\mathbf{t}$} & \multirow[t]{2}{*}{ Sig } \\
\hline & & & & $\beta$ & Error & & & \\
\hline \multirow[t]{2}{*}{ Burnout } & 89.131 & .399 & .395 & .925 & .098 & .632 & 9.441 & $(0.000)$ \\
\hline & $(0.000)$ & & & & & & & \\
\hline \multirow[t]{2}{*}{ EE } & 2.394 & .018 & .010 & -.153 & .099 & -.132 & -1.547 & .124 \\
\hline & $(.124)$ & & & & & & & \\
\hline
\end{tabular}

Table 5: Regression analysis to show the impact of Burnout on Employee Engagement

\begin{tabular}{|c|c|c|c|c|c|c|c|c|}
\hline & \multirow[t]{2}{*}{ F (Sig) } & \multirow[t]{2}{*}{$\mathbf{R}^{2}$} & \multirow[t]{2}{*}{$\operatorname{Adj} R^{2}$} & \multicolumn{2}{|c|}{$\begin{array}{c}\text { Unstandardised } \\
\text { Coefficient }\end{array}$} & \multirow[t]{2}{*}{$\begin{array}{c}\text { Standardized } \\
\text { Beta }\end{array}$} & \multirow[t]{2}{*}{$\mathbf{t}$} & \multirow[t]{2}{*}{ Sig } \\
\hline & & & & $\beta$ & Error & & & \\
\hline $\mathrm{EE}$ & 14.755 & .099 & .092 & -.248 & .065 & -.315 & -3.841 & 0.000 \\
\hline & $(0.000)$ & & & & & & & \\
\hline
\end{tabular}

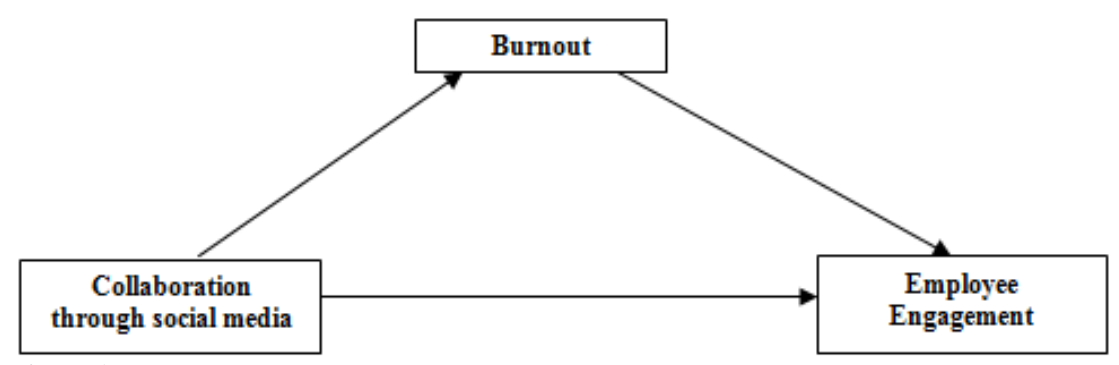

Figure 1: Model representing Burnout as a mediator between collaboration through social media and employee engagement

Table 6: Sobel test showing burnout as a mediator between collaboration through social media and employee engagement

Table 6: Sobel test showing burnout as a mediator between collaboration through social media and employee engagement
\begin{tabular}{|c|c|c|c|}
\hline & Sobel test statistics & Standard Error & p-value \\
\hline Burnout & -2.74176335 & 0.04350777 & 0.00611104 \\
\hline
\end{tabular}




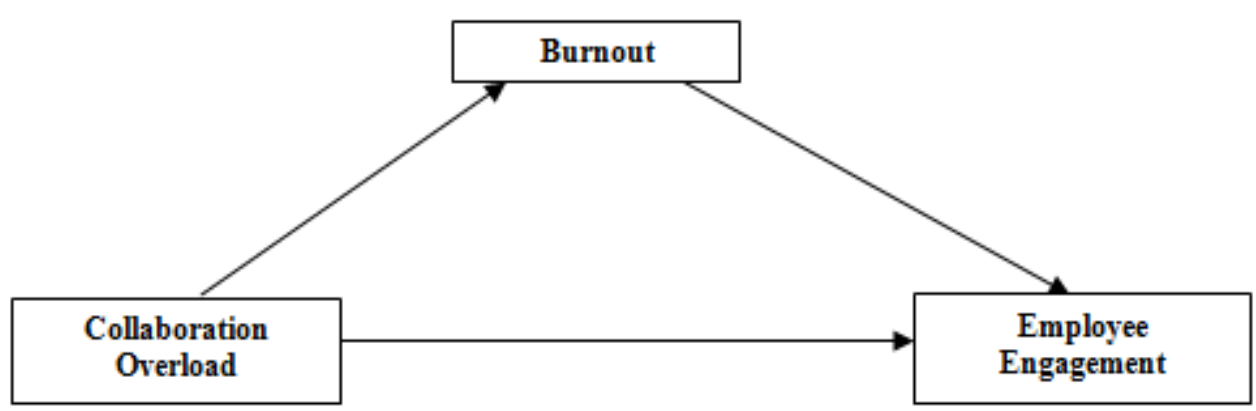

Figure 2: Model representing Burnout as a mediator between collaborative overload and employee engagement

Table 7: Sobel test showing burnout as a mediator between collaborative overload and employee engagement

\begin{tabular}{|c|c|c|c|}
\hline & Sobel test statistics & Standard Error & p-value \\
\hline Burnout & -3.53731932 & 0.06485137 & 0.00040421 \\
\hline
\end{tabular}

\section{References}

[1] Cross R, Rebele R, Grant A.Collaborative overload. Harvard Business Review.2016:94:74-79. https://hbr.org/2016/01/collaborative-overload.

[2] Harmon S, Culliman R. The Huffington Post. May 2014 https://www.huffingtonpost.com/shani-harmon/the-dark-side-of-collabor b 9825020.html

[3] Zoonen W, Verhoeven J, Vliegenthart R. Social media's dark side: Inducing boundary conflicts. Journal of Managerial Psychology. . 2016:31(8):1297-1311

[4] Cross R, Gray P. Where Has the Time Gone? Addressing CollaborationOverload in a Networked Economy. California Management Review.2013:50-66.

[5] Wisniewski P, Lu Y. When More is Too Much: Operationalizing Technology Overload and Exploring its Impact on Knowledge Worker Productivity. Computers in Human Behavior.2010:26:1061-1072.

[6] Rabey G. The paradox of teamwork. Industrial and Commercial Training.2003:35(4):158-162.

[7] Albanese R, Van Fleet, D. Rational Behavior in Groups: The Free-Riding Tendency. Academy of Management Review.1985:10(2).

[8] Lather, A. S. \& Jain, V.K. (2014). "Developing A Scale To Measure Employee Engagement”. DIAS Technological Review. 